\title{
Peanut Husk Filled Polyethylene Composites: Effects of Filler Content and Compatibilizer on Properties
}

\author{
Henry C. Obasi \\ Federal University of Technology, PMB 1526, Owerri 460221, Imo State, Nigeria \\ Correspondence should be addressed to Henry C. Obasi; neduobasi35@yahoo.com
}

Received 31 May 2015; Revised 4 August 2015; Accepted 10 August 2015

Academic Editor: José R. d’Almeida

Copyright (C) 2015 Henry C. Obasi. This is an open access article distributed under the Creative Commons Attribution License, which permits unrestricted use, distribution, and reproduction in any medium, provided the original work is properly cited.

\begin{abstract}
Agrowaste biocomposites were obtained using peanut husk filler and LDPE. The effects of agrofiller content and compatibilizer on the mechanical and biodegradable properties of the composites have been discussed. Mechanical and biodegradable behaviour of LDPE became noticeably worse when it was blended with agrofiller, due to poor compatibility between the two phases. The presence of MAPE in the composites and its compatibility with the agrofiller, led to much better dispersion and homogeneity of agrofiller in the matrix and consequently to improved properties. Water absorption and thickness swelling indices increased with increasing filler content and were reduced on addition of MAPE. Furthermore, weight loss of composites via enzymatic degradation showed that both composites were biodegradable even at high levels of filler addition. However, composites with MAPE exhibited lower weight loss.
\end{abstract}

\section{Introduction}

The geometric increase in the prices of raw materials, especially those obtained from oil and natural gas sector, and the attendant obnoxious effects of their use on the environment have triggered the strong desire in the use of raw materials from botanical resources partly or wholly for the production of plastic products. The polymers obtained from this class of raw materials (petrochemicals) are not easily degraded and form major sources of municipal solid wastes. These polymeric wastes pose a great threat to the environment because of their nondegradability and microbial resistance. The time many synthetic polymers will take to fully decompose is estimated to be around 50 decades and, during the period, natural phenomena may be influenced by the presence of these materials [1].

In order to solve the problems generated by these plastics wastes, many attempts have been made to obtain an environmentally friendly material. Over the past few decades, researches are focused on substitution of the petroleumbased plastics with biodegradable materials having similar properties and being inexpensive. Biodegradable plastics could be obtained from synthetic polymers such as polyvinyl alcohol, polycaprolactone, and polylactic acid or from natural resources such as cellulose, starch, and chitin. Recently, the use of waste agricultural biomass from different plant sources to prepare biodegradable composites with varying properties has been studied [2-7]. The use of agrowaste fillers in making polymer composites is necessitated due to the competitiveness of natural fiber with consumable crops for land use. These agrowastes are abundant, cheap, renewable, and completely biodegradable. Agrowaste fillers when used to reinforce the composites offer reasonable benefits when compared to mineral fillers $[8,9]$ : light weight, being strong and rigid, being environmentally friendly, being economical, being renewable, and being abundant. These agrowaste composites offer excellent engineering properties and provide a plausible environmental solution to handle municipal waste disposal.

However, like other natural plant based resources, agrowaste fillers have high moisture absorption tendency, have poor surface adhesion to hydrophobic polymers, are not suitable for high temperature applications, and have susceptibility to fungal and insect attack. Presently, there have been myriads of research works on the combinations of agrowastes such as palm kernel shell [10], cocoa pod husk [2], 
rice husk [11], coconut shell $[12,13]$, oil palm agrowastes $[8,14$, 15], peanut shell [16], and thermoplastic materials which had successfully been developed.

Peanut (Arachis hypogaea) is a plant grown mainly for its fruits and it is one of the world's important edible crops. The peanuts are often called groundnuts because their pods (shells) develop underground. Nigeria is the leading peanut growing country in Africa and the forth in the world after China, India, and USA. The production of peanut generates large quantities of waste peanut shells. Efforts to find utilization of these waste materials have resulted mostly in lowvalue or limited application [16]. Just as it is the case of other cellulosic materials, peanut shells contain cellulose, hemicelluloses, and lignin microfibrils, which are grouped into macrofibrils. Chemical compositions of peanut shell fiber was found to be cellulose (35.7\%), hemicelluloses (18.7\%), lignin (30.2\%), and ash content (5.9\%) [3]. Therefore, the utilization of peanut husk (shell) as natural filler in polyolefins will foster a new application route in the conversion of agrowastes to useful resources for plastic industries. This promotes the universal call for improved environmental sustainability through the reduction of municipal solid wastes and "waste to wealth" generation.

The physical and mechanical properties of thermoplastic biocomposites depend mainly on the interaction between the natural filler and the thermoplastic material. In the production of thermoplastic biocomposites, the incompatibility between the hydrophilic natural filler and hydrophobic thermoplastic matrix is an issue among researchers and industrialists.

The presence of polar hydroxyl groups of the natural filler is hardly wetted by the nonpolar polymer matrix and thus often leads to poor mechanical properties when blended [17]. One way to improve this interaction is by the incorporation of coupling agents such as compatibilizers. Maleated polymers such as maleated polyethylene (MAPE) and maleated polypropylene (MAPP) are mostly used as coupling agents in polyethylene and polypropylene based biocomposites. Several researchers have reported the reasonable improvement on properties of biocomposites by adding maleated coupling agents [18-20].

In this study, the addition of peanut husk filler to LDPE has been considered as way of enhancing the mechanical and biodegradable properties of polymeric materials obtained from these composites. Therefore, the main objective of this work is to investigate the effect of maleated PE and filler content on the various properties of agrowaste filler polymer composites.

\section{Experimental}

2.1. Materials. The low density polyethylene (LDPE) matrix used in this study was supplied by Ceeplast Industry Ltd., Aba, Nigeria. It has a density of $0.935 \mathrm{~g} / \mathrm{cm}^{3}$ and a melt flow index (MFI) of $16 \mathrm{~g} / 10 \mathrm{~min}$. Maleated polyethylene (MAPE) was obtained from Sigma-Aldrich Chemical Corporation. The agrowaste used as the reinforcing filler was peanut husks and was obtained from a local market in Ehime Mbano, Imo
State, Nigeria. The husks were processed to obtain peanut husk filler (PHF). The PHF mesh size used was $300 \mu \mathrm{m}$.

2.2. Sample Preparation. Mixtures of peanut husk filler and low density polyethylene were melt-blended in an extrusion machine at a temperature of $120-150^{\circ} \mathrm{C}$ and a screw speed of $50 \mathrm{rpm}$ to obtain PHF/LDPE composites. The PHF contents range from 0 to $25 \mathrm{wt}$.\% in the blends. Maleated polyethylene (MAPE) was used as a compatibilizer at $5 \mathrm{wt}$.\% based on the filler loading. The liquid melt was extruded as flats sheets. These sheets were oven-dried over night at $70^{\circ} \mathrm{C}$ to reduce moisture content and kept in air tight container for at least $40 \mathrm{~h}$ according to ASTM D618.

2.3. Tensile Test. Tensile tests were carried out using a universal Instron tensile tester 3366 according to ASTM D638 with the samples obtained as described. Tensile properties were measured at room temperature at $5 \mathrm{~mm} / \mathrm{min}$ crosshead speed to obtain the tensile strength, elongation at break, and Young's modulus. Averaged values of five runs of each were obtained.

2.4. Flexural Test. The flexural test was performed using the same universal testing machine used for tensile test in accordance with ASTM D790 with a three-point bending geometry at a crosshead speed of $2 \mathrm{~mm} / \mathrm{min}$ to evaluate the flexural strength and modulus under a load cell of $1 \mathrm{kN}$. Average values of five samples were calculated.

2.5. Impact Test. The impact test was conducted on notched rectangular samples according to ASTM D256 using an impact tester (IZOD Impact tester), with a $4.0 \mathrm{~J}$ hammer. Average values were obtained from five runs for each sample.

2.6. Hardness Test. The hardness test of the composite samples was conducted using Lecco Vickers (LV 700) testing machine according to ASTM D78. Average values of five runs were calculated.

2.7. Water Absorption Test. The water absorption study of the composites was determined according to ASTM D570. Cut samples of dimensions $30 \times 30 \times 3 \mathrm{~mm}^{3}$ were dried in a vacuum at $45^{\circ} \mathrm{C}$ for $24 \mathrm{~h}$, weighed to get the initial dry weight to the nearest $0.001 \mathrm{~g}$, and then immersed in distilled water for a period of 63 days. Weights of the samples were measured after every 7 days to obtain the new change in weight. The percent water absorption $\left(P_{\text {wa }}\right)$ was calculated as follows:

Percent water absorption $\left(P_{\text {wa }}\right)$

$$
=100\left[\left(\frac{\text { Final dry wt. after immersion }}{\text { Initial dry wt. before immersion }}\right)-1\right] \text {. }
$$

2.8. Thickness Swelling Test. Thickness swelling test is akin to water absorption test. Before testing, the initial thickness of each sample was measured using a digital veneer caliper and later immersed in distilled water at room temperature. After 7 days, the sample was taken out and dried before its new 
thickness was measured. The percent thickness swelling $\left(P_{\mathrm{ts}}\right)$ was determined as follows:

$$
\begin{aligned}
& \text { Percent thickness swelling }\left(P_{\mathrm{ts}}\right) \\
& \quad=100\left[\left(\frac{\text { Final thickness }}{\text { Initial thickness }}\right)-1\right] .
\end{aligned}
$$

2.9. Enzymatic Degradation Test. The composite sample of dimensions $30 \times 30 \times 3 \mathrm{~mm}^{3}$ is added into a conical flask containing $30 \mathrm{~mL}$ acetate buffer $(\mathrm{pH}=4.5)$ with cellulase concentration of $2 \mathrm{~g} / \mathrm{L}$. The mixture was then placed in a shaking incubator at $55^{\circ} \mathrm{C}$ and shaken at $60 \mathrm{rpm}$ for $54 \mathrm{~h}$. After every $6 \mathrm{~h}$, the sample was washed with distilled water and then dried in a vacuum at $45^{\circ} \mathrm{C}$ for $24 \mathrm{~h}$. The immersion medium was refreshed regularly to maintain enzymatic activity. The extent of enzymatic degradation (EED) was estimated from the weight loss of the sample based on the following equation:

$$
\operatorname{EED}(\%)
$$

$$
=100\left[1-\left(\frac{\text { Final dry wt. after treatment }}{\text { Initial dry wt. before treatment }}\right)\right] .
$$

\section{Results and Discussion}

3.1. Tensile Tests. Filler volume fraction and filler/matrix interfacial adhesion are fundamental factors that affect the mechanical properties of fiber-reinforced composites. The quality of interfacial adhesion is dependent on a number of factors such as the nature of filler and polymer components, the filler aspect ratio, the processing method, and the treatment of the filler [21, 22]. The experimental results of tensile tests of compatibilized CPHF/LDPE and uncompatibilized PHF/LDPE composites are displayed in Figures 1-3. These figures depict the tensile properties in relation to the filler content. The addition of peanut husk filler (amorphous in nature) reduced the tensile strength which continuously decreased with increasing filler content (Figure 1). The reduction in tensile strength could be due to filler-filler interaction, which becomes more pronounced than that of the filler-matrix interactions. Another factor could be poor interfacial adhesion due to differences in polarities between the polar agrowaste filler and nonpolar LDPE matrix which could initiate and propagate sites for failures. Similar observations have also been reported in our previous work [23] and by other researchers using natural fillers [11, 24-29]. The addition of MAPE improved the tensile strength when compared with the corresponding PHF/LDPE composites. This is because the reactive maleic anhydride group on MAPE chemically reacted with hydroxyl group of peanut husk filler surface and the MAPE was covalently bonded to peanut husk filler through esterification.

This mechanism offers a better compatibility to LDPE matrix and more efficient interfacial adhesion. The schematic reaction of PHF, MAPE, and LDPE matrix is shown in Figure 4. Improvement on tensile properties of biocomposites using maleated polyolefin has been studied [2, 25, 30-32].

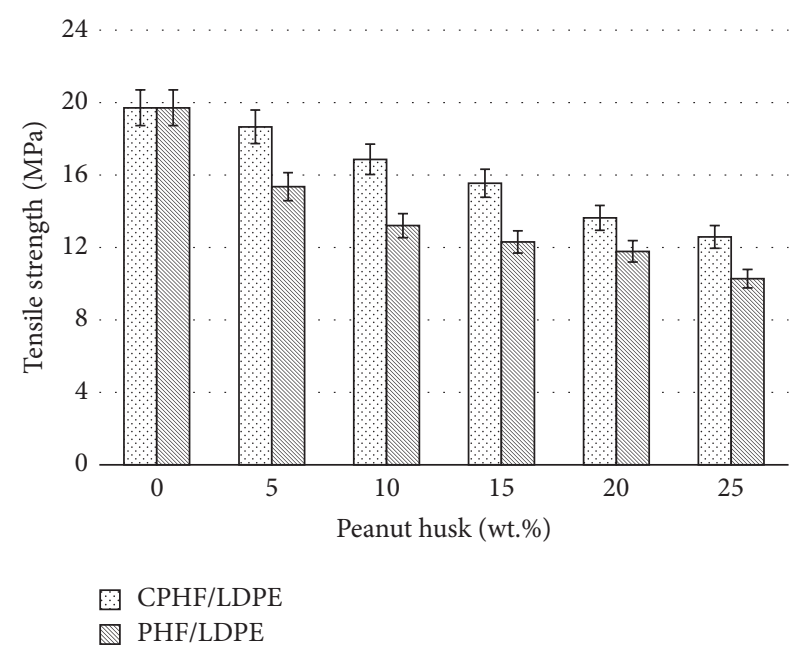

FIGURE 1: Variation of tensile strength at different filler content.

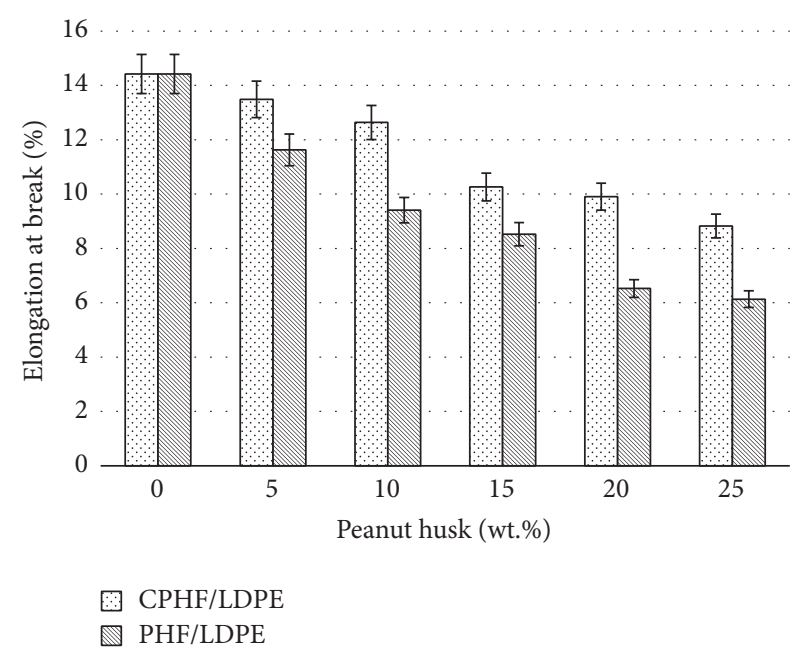

FIGURE 2: Variation of elongation at break at different filler content.

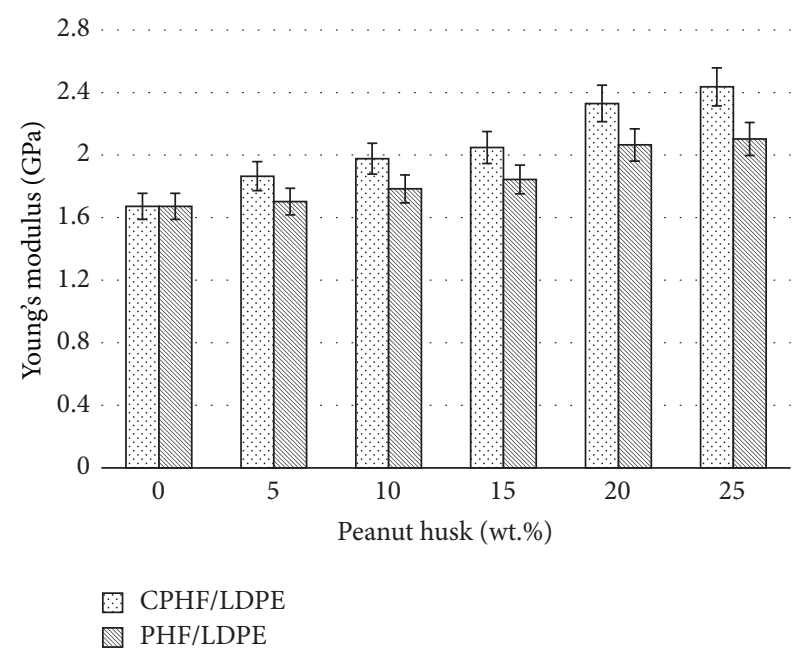

FIgURE 3: Variation of Young's modulus at different filler content. 


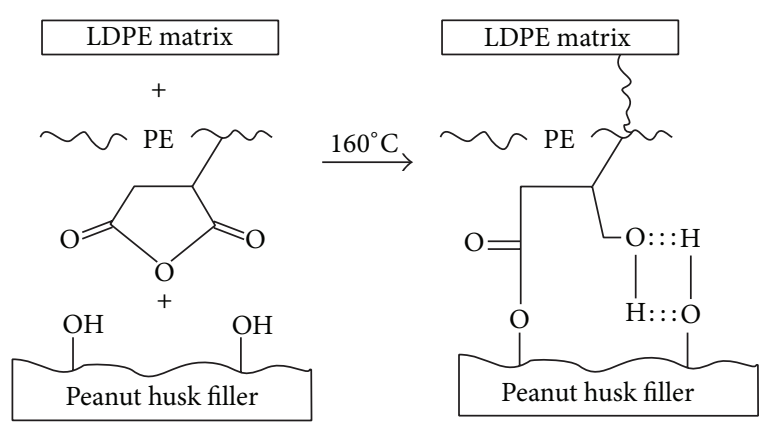

FIgURE 4: Schematic reaction between PHF, MAPE, and PE matrix.

The effect of filler content on the elongation at break of the PHF/LDPE biocomposites is illustrated in Figure 2. It is evident in the figure that the elongation at break decreases with increasing filler loading. Reduction of elongation at break is common since weakly or feasible bonds exist between agrowaste filler and LDPE. At higher filler content, a drastic reduction of elongation at break was observed and was mostly common in biocomposites. Again, weak interfacial bonds due to poor filler/LDPE interaction facilitated crack propagation and thus composites fracture at lower value of elongation was obtained with increasing filler content. Furthermore, the addition of PHF stiffened the composites, thereby decreasing their ductility. The elongation at break of the compatibilized composites gave us better results than the uncompatibilized composites. The same reasons earlier advanced for the tensile strength, which greatly depend on the nature of the filler and LDPE. The presence of MAPE functioned as a bridge between two dissimilar materials.

Figure 3 shows Young's modulus of the PHF/LDPE composites at different filler contents. It is evident that the modulus increases with the addition of PHF into LDPE. The presence of fillers hindered the polymer chain mobility of LDPE matrix, in addition to the stiffness of the composite $[33,34]$. The rigidity of the composite could also be linked to the cellulose contents of the peanut husk fillers. Young's modulus increase with filler content was in agreement with other reported works [11, 29, 35, 36]. For the MAPE modified PHF/LDPE composites, the introduction of the polar groups in MAH enhanced the composites rigidity and compatibility simultaneously and changed the intrinsic properties of the matrix. Young's modulus of the composite corresponded to the intrinsic properties of the filler, where the filler may show its high stiffness [36]. Above all, several researchers have shown that the incorporation of compatibilizers enhances interfacial bonding via steric stabilization [37] and good wetting and reduction in surface tension [38]. It could be possible that similar scenario played out itself in this system above.

3.2. Flexural Properties. For a composite to be considered as structural materials, it must possess a considerable amount of flexural properties. The flexural strength and flexural modulus of both compatibilized and uncompatibilized PHF/LDPE composites of different filler loadings are shown in Figures 5 and 6 , respectively.

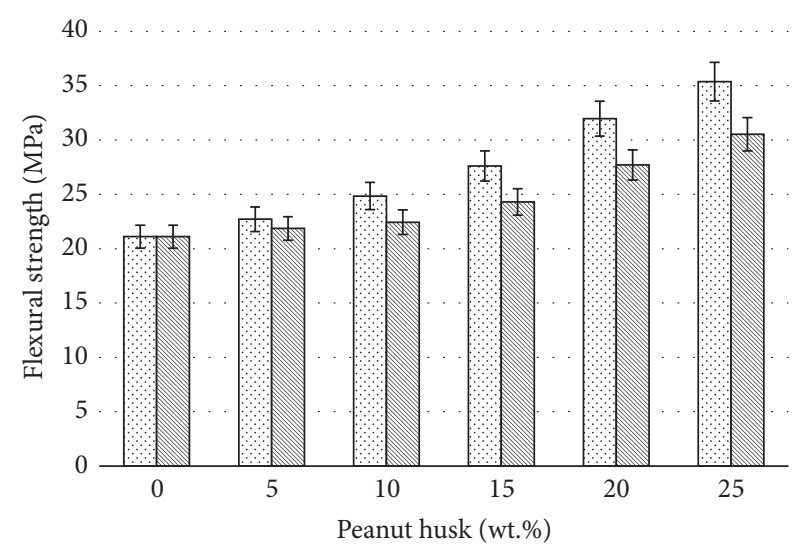

CPHF/LDPE
$\mathbb{N}$ PHF/LDPE

FIGURE 5: Variation of flexural strength at different filler content.

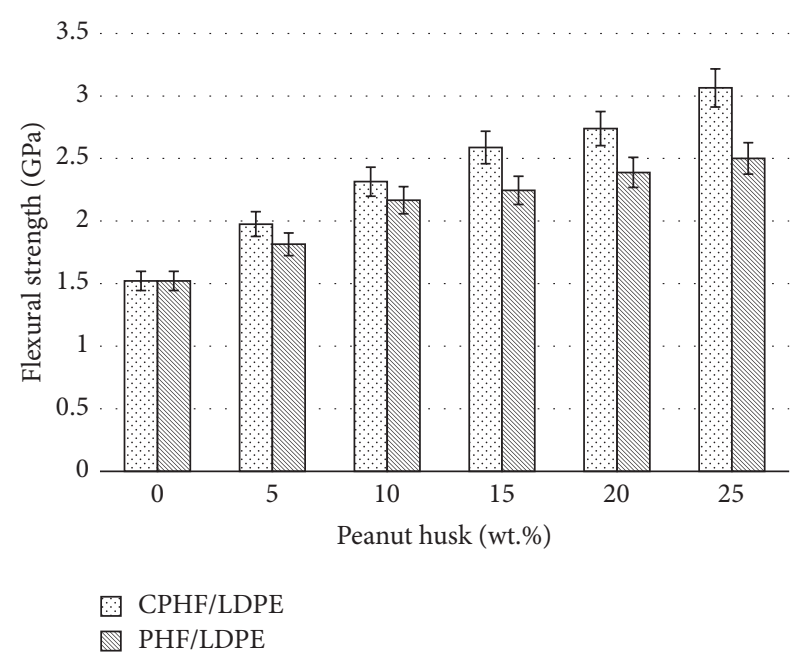

Figure 6: Variation of flexural modulus at different filler content.

The neat LDPE polymer showed flexural strength of $21.104 \mathrm{MPa}$ and increased linearly on addition of peanut husk filler by $44.65 \%$ up to $25 \mathrm{wt} . \%$ PHF for uncompatibilized PHF/LDPE composites as shown in Figure 5. This result agrees with the findings of many researchers using natural fillers to blend synthetic polymers; Tawakkal et al. [39] observed an appreciable increase in the flexural strength of the composite from 10 to $60 \mathrm{wt}$ \% KDC (Kenaf-derived cellulose) when compared to that of neat PLA (polylactic acid), but they noticed that, above $50 \mathrm{wt} . \% \mathrm{KDC}$, the flexural strength decreased with increasing KDC content. Similar trend was also observed by Rahman et al. [40] where the flexural strength increased with RH (rice husk) filler addition up to $35 \mathrm{wt} . \%$ and beyond that the flexural strength decreased. It is also observed that the flexural strength of PHF/LDPE composites further improved by $67.58 \%$ on the incorporation of MAPE which can be attributed to a well-formed interface that allows better stress transfer from the matrix to the filler. 
The addition of MAPE positively modified the adhesive characteristics of the composite by improving the mechanical interlocking between the PHF and LDPE and thus improves the stress transfer during an applied load.

Figure 6 shows that the flexural modulus of PHF/LDPE composites increased with the filler loading. The rigidity of the PHF, combined with its higher content, may be linked to enhanced bending modulus of PHF/LDPE composites.

The PHF might obstruct the free flow of the polymer chain and thus restrict the ability of the polymer to deform. Similar results have been also reported by other scholars with various reinforcement materials [35, 36, 41, 42]. Flexural modulus of PHF/LDPE modified with MAPE exhibited better result with a $50.33 \%$ and $18.57 \%$ increase over unmodified PHF/LDPE and neat LDPE at $25 \mathrm{wt} . \%$, respectively. This could be linked to the improved interfacial bonding between the filler and matrix. The increased composites stiffness depends on the nature of the filler, filler content, and the uniformity of the filler dispersion. These observations are supported by Cañigueral et al. [43], who concluded that good filler dispersion in the composite system could be confirmed by observing the linear increase in the composites modulus. The addition of MAPE offers a better bridging between the filler and matrix via esterification reactions which results in good stress propagation and improves mechanical characteristics.

3.3. Impact Strength. Figure 7 presents the effects of PHF contents on the notched Izod impact strength of both compatibilized and uncompatibilized PHF/LDPE composites. The figure shows that the impact strength increased with filler content. At $25 \mathrm{wt} . \%$ filler content, PHF/LDPE had impact strength of $49.38 \%$ increment. Similar results were also obtained for different natural filler filled composites [36, $39,40,44]$ up to $35 \mathrm{wt} . \%$ content beyond which the impact strength dropped.

The decrease in impact strength indicates that the amount of matrix is probably not sufficient to transfer the stress effectively during a sudden impact in combination with the lower absorption characteristic of the filler [39]. It has been observed that high filler content increases the chances of fiber agglomeration, which results in regions of stress concentration requiring less energy for crack propagation [45]. Joseph et al. [46] reported that the impact strength of fiber filled polymer composites depends on the nature of the filler, the polymer, and fiber matrix interfacial bonding. The impact strengths of MAPE modified PHF/LDPE composites were found to be higher than the unmodified PHE/LDPE composites, thus achieving 20.95\% increment over the unmodified PHF/LDPE composites. This may be attributed to the same reason earlier advanced for tensile and flexural strengths.

3.4. Hardness Result. The hardness behavior of various PHF/ LDPE composites of different filler content for both with compatibilizer and without compatibilizer is shown in Figure 8. The figure indicates that the mean hardness increased with increase in filler content. This may be linked to the increase in stiffness occasioned by the presence of

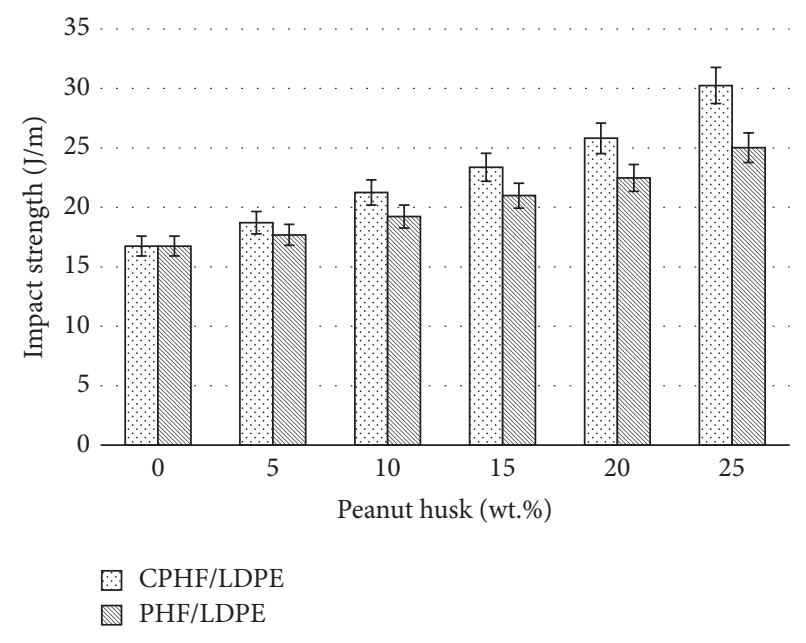

Figure 7: Variation of impact strength at different filler content.

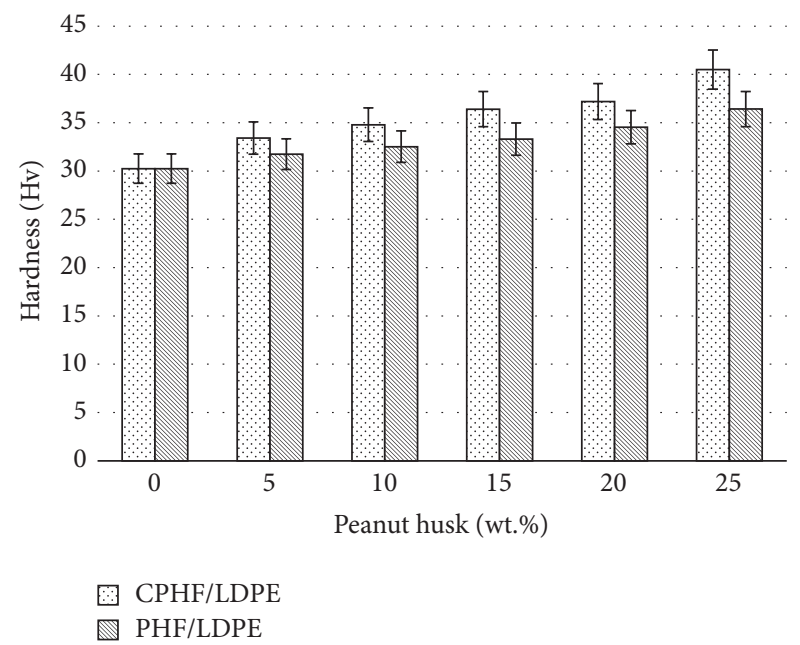

FIGURE 8: Variation of hardness at different filler content.

rigid fillers in the matrix. Composites with compatibilizer exhibited higher values of hardness that the uncompatibilizer composites. The increase in hardness of the compatibilized composites may be due to stronger interfacial bonding of the peanut husk filler and low density polyethylene matrix.

3.5. Water Absorption Study. Figures 9 and 10 represent the water absorption indices of PHF/LDPE composites at different filler contents for compatibilized and uncompatibilized PHF/LDPE composites, respectively. The degree of water absorption in natural fiber reinforced composites is dependent on temperature, fiber content, orientation of fibers, permeability of fiber, surface protection, area of the exposed surface, diffusivity, void content, hydrophilicity of the individual components, and so forth [45]. Results indicated that water absorption increased gradually with increase in filler content, reaching a saturation point where the moisture 


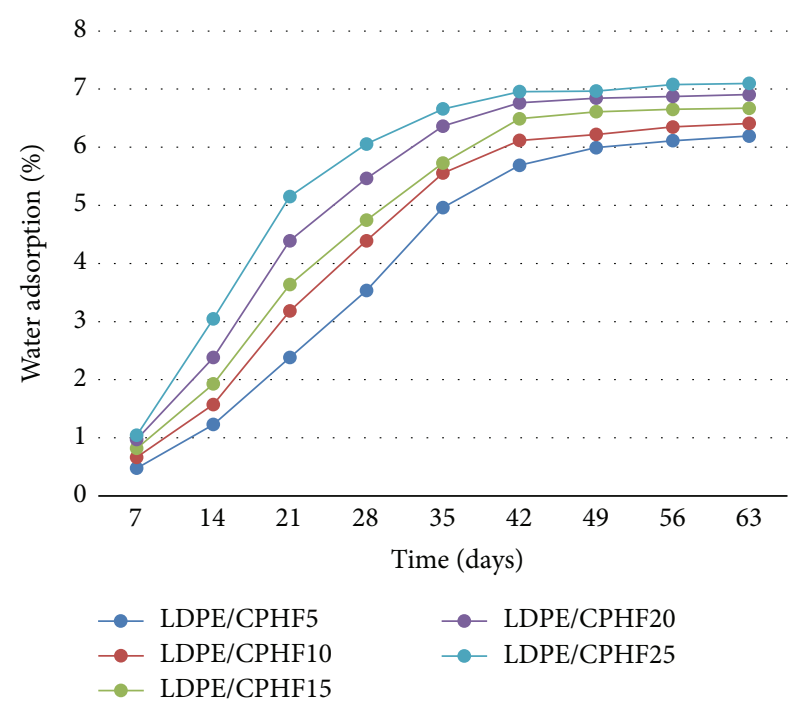

Figure 9: Water absorption of CPHF/LDPE at different filler content.

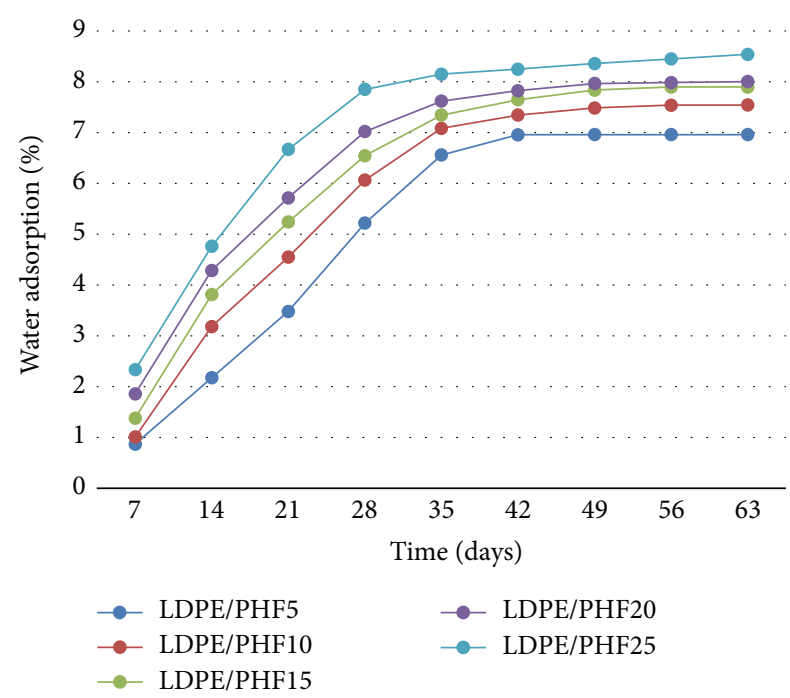

FIGURE 10: Water absorption of PHF/LDPE at different filler content.

content almost remained constant. This observation is due to the hydrophilic nature of natural filler which is responsible for the water absorption in the composites by virtue of the presence of abundant hydroxyl groups [39]. Thus, higher filler content led to a higher amount of water being absorbed. It is worthy to note that water molecules can wet the PHF/LDPE composites easily and also penetrate into the composites through voids with the resultant in higher water index in a short exposure time $[47,48]$.

However, compatibilized PHF/LDPE composites exhibited lower percentage of water absorption in comparison with the uncompatibilized components. Figure 10 shows that, at each filler content, PHF/LDPE composites, with the addition of MAPE, show lower percentage of water absorbed relative to PHF/LDPE without the compatibilizer (MAPE). This may be due to the presence of less voids and cracks as a result of good interfacial bonding which is formed between the PHF/MAPE/LDPE as earlier discussed. It could be said that the better the compatibility of the polymer composites is, the greater the reduction of the penetrant molecules into composites would be. This behaviour suggests that the composites with MAPE have better compatibility between the PHF and LDPE matrices than those without MAPE.

3.6. Thickness Swelling Study. Thickness swelling study was carried out simultaneously with water absorption procedure. Figures 11 and 12 show the thickness swelling behaviours of various PHF/LDPE composites. It can be clearly seen that thickness swelling increased with immersion time and filler content. Swelling occurs when the liquid diffuses within the composite material and is absorbed by the composites. When the immersion time of composites is increased, an appreciable amount of water is absorbed, resulting in the swelling of the filler and possible saturation of the cell walls. This scenario can be related to the degree of the hydrolysis mechanism of peanut husk filler of the composite in distilled water. Above that, water exists as free water in the voids, which leads to composite delamination or void formation [49, 50]. Compatibilized PHF/LDPE composites showed lower thickness swelling compared to uncompatibilized PHF/LDPE composites (Figure 11). The decrease in thickness swelling may be attributed to the improved interfacial adhesion between the filler and matrix. The presence of MAPE reduces or eliminates microvoids and crack formation in the composites which ordinarily would have created pathways for the water molecules to diffuse into the composites.

3.7. Enzymatic Studies. The enzymatic degradation of cellulose or cellulosic containing materials, typically characterized by an insoluble reactant (cellulosic substrate) and a soluble catalyst (enzyme-cellulase), is influenced not only by the structural factors of the solid substrate but also by enzyme related factors, such as enzyme source, product inhibition, thermal inactivation, activity bonding and enzyme processability, and enzyme compatibility [51]. The weight loss due to enzyme degradation of PHF/LDPE composites for both modified and unmodified composites is shown in Figures 13 and 14. It is observed that the extent of enzyme degradation (EED) increased with increase in filler content and immersion time. A higher degradation rate was observed for uncompatibilized PHF/LDPE composites than the compatibilized PHF/LDPE composites after 63 days of study. This trend was due to the poor interfacial adhesion existing in PHF/LDPE which facilitated the absorption of enzymes into the composites. At high filler content, the PHF/LDPE composites absorb more of the cellulase solution because of excess hydroxyl group that enhanced the cellulase attack on the peanut husk filler. Therefore, the peanut husk filler content affected the weight loss of the composites. Similar results have been obtained by Mohammad and Narges [52], Michael [53], and Azahari et al. [54]. 


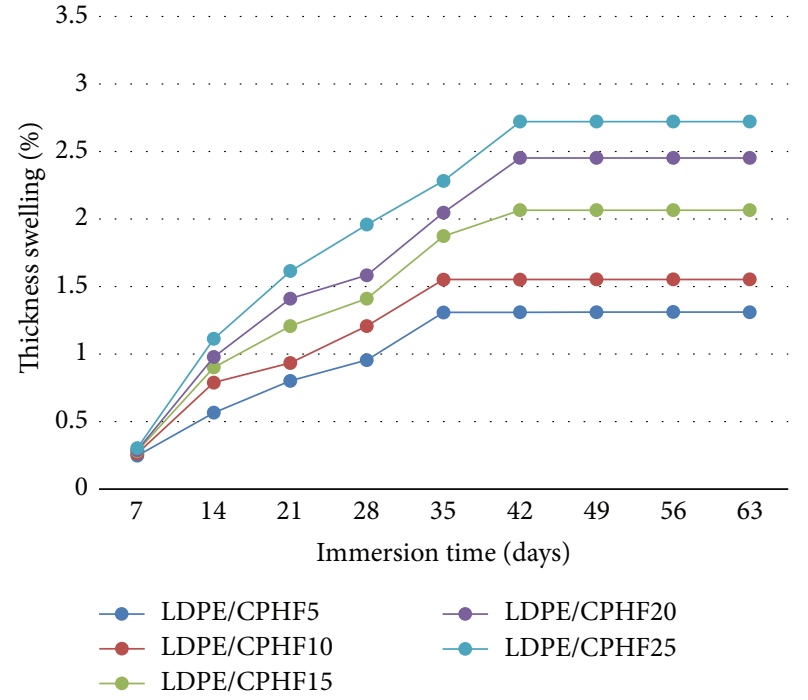

FIGURE 11: Variation of thickness of CPHF/LDPE at different filler content.

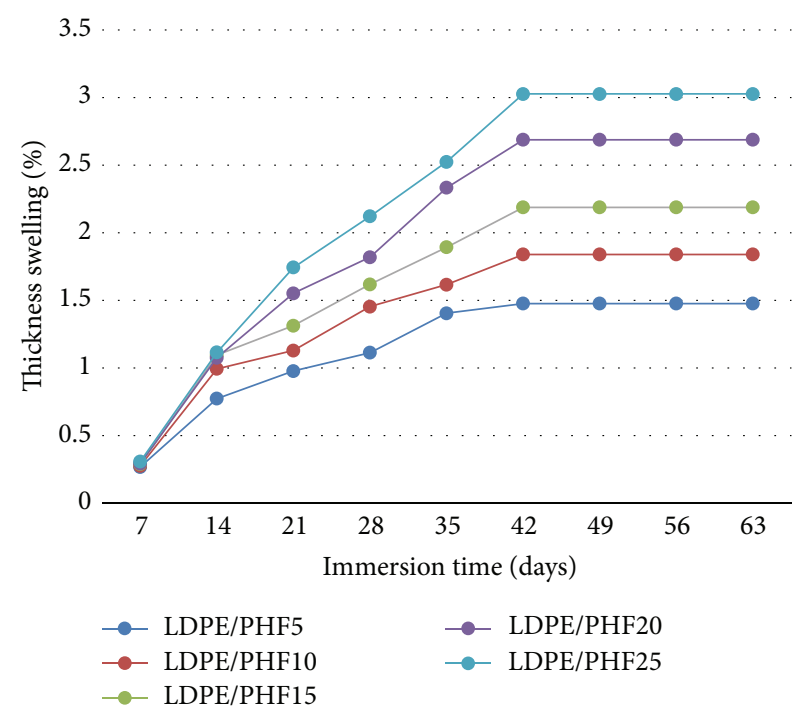

FIGURE 12: Variation of thickness of PHF/LDPE at different filler content.

\section{Conclusions}

The main conclusions drawn from this work were as follows:

(1) A biocomposite was successfully fabricated from peanut husk filler and LDPE and utilizing compatibilization modification process.

(2) Higher filler content in LDPE decreases the tensile strength and elongation at break due to weak interfacial bonding between the PHF and LDPE matrices.

(3) Young's modulus, flexural strength and modulus, impact strength and hardness increased with increase in filler content and the addition of MAPE into

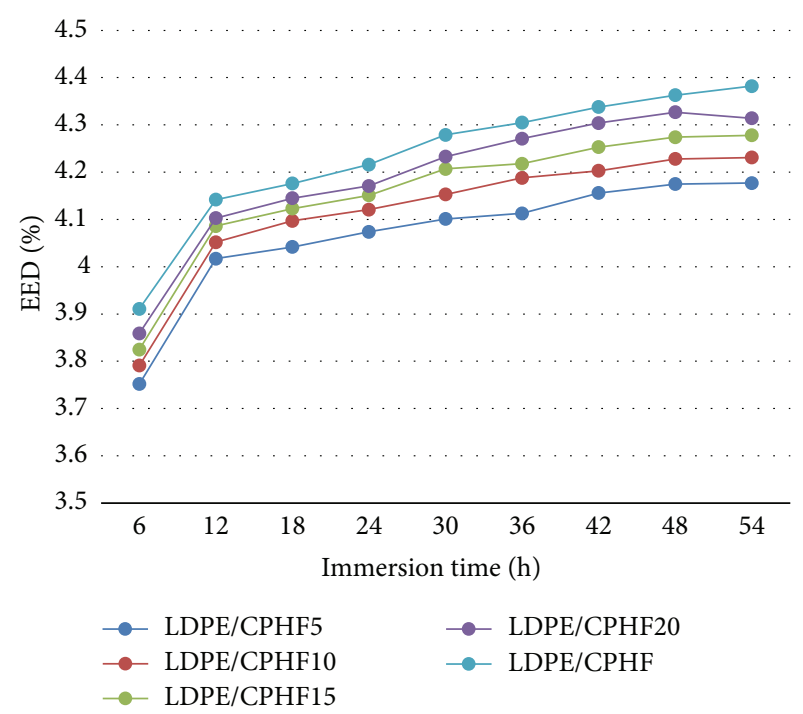

FIGURE 13: Enzymatic degradation CPHF/LDPE at different filler content.

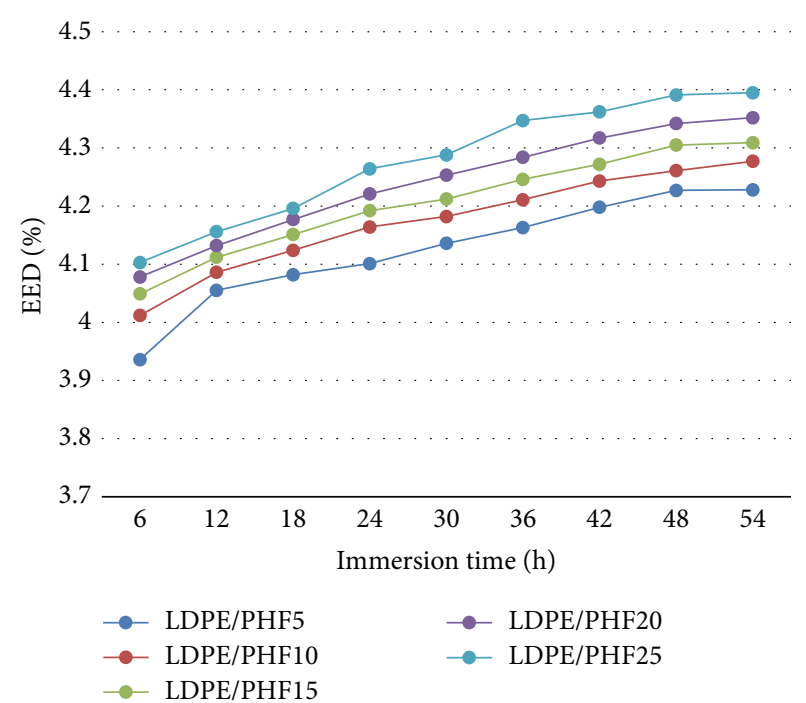

FIgURE 14: Enzymatic degradation of PHF/LDPE at different filler content.

the composite is necessary to improve the tensile properties.

(4) The modification of the PHF/LDPE composites via compatibilization enhanced the interfacial adhesion at the filler/matrix interphase as indicated by the reduction in water absorption and thickness swelling of the composites.

(5) Presence of compatibilizer (MAPE) improved the interfacial adhesion between the filler and matrix by lowering the percent weight loss via enzymatic degradation of the PHF/LDPE composites as shown by the compatibilized composites. 


\section{Conflict of Interests}

The author declares that there is no conflict of interests regarding the publication of this paper.

\section{References}

[1] M. Saeed, G. Ismail, and O. Abdulrasoul, "Effect of compatibilization onpolyethylene/thermoplasticstarch blends," Society of Plastic Engineers, Plastics Research Online, pp. 1-3, 2013.

[2] K. S. Chun, S. Husseinsyah, and H. Osman, “Tensile properties of polypropylene/cocoa pod husk biocomposites: effect of maleated polypropylene," Advanced Materials Research, vol. 747, pp. 645-648, 2013.

[3] G. U. Raju, S. Kumarappa, and V. N. Gaitonde, "Mechanical and physical characterization of agricultural waste reinforced polymer composites," Journal of Materials and Environmental Science, vol. 3, no. 5, pp. 907-916, 2012.

[4] G. U. Raju, V. N. Gaitonde, and S. Kumarappa, "Experimental study on optimization of thermal properties of groundnut shell particle reinforced polymer composites," International Journal of Emerging Sciences, vol. 2, no. 3, pp. 433-454, 2012.

[5] A. Ashori and A. Nourbakhsh, "Bio-based composites from waste agricultural residues," Waste Management, vol. 30, no. 4, pp. 680-684, 2010.

[6] S. L. Fávaro, M. S. Lopes, A. G. V. D. C. Neto, R. R. de Santana, and E. Radovanovic, "Chemical, morphological, and mechanical analysis of rice husk/post-consumer polyethylene composites," Composites Part A: Applied Science and Manufacturing, vol. 41, no. 1, pp. 154-160, 2010.

[7] S. S. Ahankari, A. K. Mohanty, and M. Misra, "Mechanical behaviour of agro-residue reinforced poly(3-hydroxybutyrateco-3-hydroxyvalerate), (PHBV) green composites: a comparison with traditional polypropylene composites," Composites Science and Technology, vol. 71, no. 5, pp. 653-657, 2011.

[8] H. P. S. Abdul Khalil, B. T. Poh, A. M. Issam, M. Jawaid, and R. Ridzuan, "Recycled polypropylene-oil palm biomass: the effect on mechanical and physical properties," Journal of Reinforced Plastics \& Composites, vol. 29, no. 8, pp. 1117-1130, 2010.

[9] R. Malkapuram, V. Kumar, and Y. Singh Negi, "Recent development in natural fiber reinforced polypropylene composites," Journal of Reinforced Plastics and Composites, vol. 28, no. 10, pp. 1169-1189, 2009.

[10] H. Salmah, A. Romisuhani, and H. Akmal, "Properties of lowdensity polyethylene/palm kernel shell composites: effect of polyethylene co-acrylic acid," Journal of Thermoplastic Composite Materials, vol. 26, no. 1, pp. 3-15, 2013.

[11] H.-S. Yang, H.-J. Kim, J. Son, H.-J. Park, B.-J. Lee, and T.S. Hwang, "Rice-husk flour filled polypropylene composites: mechanical and morphological study," Composite Structures, vol. 63, no. 3-4, pp. 305-312, 2004.

[12] K. S. Chun, S. Husseinsyah, and H. Osman, "Properties of coconut shell powder-filled polylactic acid ecocomposites: effect of maleic acid," Polymer Engineering and Science, vol. 53, no. 5, pp. 1109-1116, 2013.

[13] H. Salmah, S. C. Koay, and O. Hakimah, "Surface modification of coconut shell powder filled polylactic acid biocomposites," Journal of Thermoplastic Composite Materials, vol. 26, no. 6, pp. 809-819, 2013.

[14] H. C. Obasi, I. O. Igwe, G. N. Onyeagoro, M. U. Obidiegwu, and P. I. Anyanwu, "Oil palm mesocrap particles reinforced cashew nut shell novolac resin composites," Applied Polymer Composites, vol. 2, no. 1, pp. 27-36, 2014.

[15] H. C. Obasi, N. C. Iheaturu, F. N. Onuoha, C. O. ChikeOnyegbula, M. N. Akanbi, and V. O. Eze, "Influence of alkali treatment and fibre content on the properties of oil palm press fibre reinforced epoxy biocomposities," American journal of Engineering Research, vol. 3, no. 2, pp. 117-123, 2014.

[16] N. F. Zaaba, H. Ismail, and M. Jaafar, "The effects of modifying peanut shell powder with polyvinyl alcohol on the properties of recycled polypropylene and peanut shell powder composites," BioResources, vol. 9, no. 2, pp. 2128-2142, 2014.

[17] S. Tserki, P. Matzinos, S. Kokkou, and C. Panayiotou, "Novel biodegradable composite based on treated lignocellulosic waste and characterization of waste flour," Composites Part A, vol. 36, pp. 965-974, 2005.

[18] H. Salmah and H. Ismail, "The effect of filler loading and maleated polypropylene on properties of rubberwood filled polypropylene/natural rubber composites," Journal of Reinforced Plastics and Composites, vol. 27, no. 16-17, pp. 1867-1876, 2008.

[19] A. K. Bledzki, O. Faruk, and M. Huque, "Physico-mechanical studies of wood fiber reinforced composites," Polymer-Plastics Technology and Engineering, vol. 41, no. 3, pp. 435-451, 2002.

[20] N. Sombatsompop, C. Yotinwattanakumtorn, and C. Thongpin, "Influence of type and concentration of maleic anhydride grafted polypropylene and impact modifiers on mechanical properties of PP/wood sawdust composites," Journal of Applied Polymer Science, vol. 97, no. 2, pp. 475-484, 2005.

[21] A. Gomes, T. Matsuo, K. Goda, and J. Ohgi, "Development and effect of alkali treatment on tensile properties of curaua fiber green composites," Composites Part A: Applied Science and Manufacturing, vol. 38, no. 8, pp. 1811-1820, 2007.

[22] M. Pracella, D. Chionna, I. Anguillesi, Z. Kulinski, and E. Piorkowska, "Functionalization, compatibilization and properties of polypropylene composites with Hemp fibres," Composites Science and Technology, vol. 66, no. 13, pp. 2218-2230, 2006.

[23] H. C. Obasi, "Properties of raphia palm interspersed fibre filled high density polyethylene," Advances in Materials Science and Engineering, vol. 2013, Article ID 932143, 5 pages, 2013.

[24] M. A. Wahab and M. A. Mottaleb, "Mechanical properties and water absorption of rice starch-filled linear low density polyethylene," Korea Polymer Journal, vol. 9, no. 6, pp. 297-302, 2001.

[25] H. C. Obasi and G. C. Onuegbu, "Biodegradability and mechanical properties of low density polyethylene/waste maize cob flour blends," International Journal of Applied Science and Engineering Research, vol. 2, no. 3, pp. 242-249, 2013.

[26] S. B. Nurshamila, I. Hnafi, and O. Nadras, "The effect of Rattan filler loading on properties of Rattan powder filled polypropylene composites," BioResources, vol. 7, no. 4, pp. 56775690, 2012.

[27] H. Demir, U. Atikler, D. Balköse, and F. Tihmınlığlu, “The effect of fiber surface treatments on the tensile and water sorption properties of polypropylene-luffa fiber composites," Composites Part A: Applied Science and Manufacturing, vol. 37, no. 3, pp. 447-456, 2006.

[28] H.-S. Yang, H.-J. Kim, H.-J. Park, B.-J. Lee, and T.-S. Hwang, "Water absorption behavior and mechanical properties of lignocellulosic filler-polyolefin bio-composites," Composite Structures, vol. 72, no. 4, pp. 429-437, 2006.

[29] M. M. Thwe and K. Liao, "Effects of environmental aging on the mechanical properties of bamboo-glass fiber reinforced 
polymer matrix hybrid composites," Composites Part A: Applied Science and Manufacturing, vol. 33, no. 1, pp. 43-52, 2002.

[30] J. Z. Lu, I. I. Negulescu, and Q. Wu, "Maleated wood-fiber/highdensity-polyethylene composites: coupling mechanisms and interfacial characterization," Composite Interfaces, vol. 12, no. 12, pp. 125-140, 2005.

[31] R. A. Majid, H. Ismail, and R. M. Taib, "Effects of polyethyleneg-maleic anhydride on properties of low density polyethylene/thermoplastic sago starch reinforced kenaf fibre composites," Iranian Polymer Journal, vol. 19, no. 7, pp. 501-510, 2010.

[32] B. Imre and B. Pukánszky, "Compatibilization in bio-based and biodegradable polymer blends," European Polymer Journal, vol. 49, no. 6, pp. 1215-1233, 2013.

[33] S. T. Sam, H. Ismail, and Z. Ahmad, "Linear low-density polyethylene/(soya powder) blends containing polyethylene-g(maleic anhydride) as a compatibilizer," Journal of Vinyl and Additive Technology, vol. 15, no. 4, pp. 252-259, 2009.

[34] R. Santiagoo, H. Ismail, and K. Hussin, "Mechanical properties, water absorption, and swelling behaviour of rice husk powder filled polypropylene/recycled acrylonitrile butadiene rubber (pp/nbrr/rhp) biocomposites using silane as a coupling agent," BioResources, vol. 6, no. 4, pp. 3714-3726, 2011.

[35] A. K. Rana, A. Mandal, and S. Bandyopadhyay, "Short jute fibre reinforced polypropylene composites: effect of compatibilizer, impact modifier and fiber loading," Composites Science and Technology B, vol. 34, pp. 519-526, 2003.

[36] S. Joseph, M. S. Sreekala, T. Oommen, P. Koshy, and S. A. Thomas, "Comparison of mechanical properties of phenol formaldehyde composite reinforced with banana fibres and glass fibres," Composites Science and Technology, vol. 62, pp. 1857-1865, 2002.

[37] A. G. Supri, S. J. Tan, H. Ismail, and P. L. Teh, "Effect of poly(methyl methacrylate) modified water hyacinth fiber on properties of low density polyethylene/natural rubber/water hyacinth fiber composites," Polymer-Plastics Technology and Engineering, vol. 50, no. 9, pp. 898-906, 2011.

[38] R. B. Maliger, S. A. McGlashan, P. J. Halley, and L. G. Matthew, "Compatibilization of starch-polyester blends using reactive extrusion," Polymer Engineering and Science, vol. 46, no. 3, pp. 248-263, 2006.

[39] I. S. M. A. Tawakkal, R. A. Talib, K. Abdan, and C. N. Ling, "Mechanical and physical properties of kenaf-derived cellulose (KDC)-filled polylactic acid (PLA) composites," BioResources, vol. 7, no. 2, pp. 1643-1655, 2012.

[40] M. R. Rahman, M. N. Islam, M. M. Huque, S. Hamdan, and A. S. Ahmed, "Effect of chemical treatment on rice husk (RH) reinforced polyethylene (PE) composites," BioResources, vol. 5, no. 2, pp. 854-869, 2010.

[41] J. C. Lin, L. C. Chang, M. N. Nien, and H. L. Ho, "Mechanical behaviour of various nanoparticle filled composites at lowvelocity impact," Composite Structures, vol. 27, pp. 30-36, 2006.

[42] P. N. Khanam, H. P. S. A. Khalil, M. Jawaid, G. R. Reddy, C. S. Narayana, and S. V. Naidu, "Sisal/carbon fibre reinforced hybrid composites: tensile, flexural and chemical resistance properties," Journal of Polymers and the Environment, vol. 18, no. 4, pp. 727-733, 2010.

[43] N. Cañigueral, F. Vilaseca, J. A. Méndez et al., "Behavior of biocomposite materials from flax strands and starch-based biopolymer," Chemical Engineering Science, vol. 64, no. 11, pp. 2651-2658, 2009.
[44] C.-W. Lou, C.-W. Lin, C.-H. Lei et al., "PET/PP blend with bamboo charcoal to produce functional composites," Journal of Materials Processing Technology, vol. 192-193, pp. 428-433, 2007.

[45] P. A. Sreekumar, K. Joseph, G. Unnikrishnan, and S. Thomas, "A comparative study on mechanical properties of sisal-leaf fibre-reinforced polyester composites prepared by resin transfer and compression moulding techniques," Composites Science and Technology, vol. 67, no. 3-4, pp. 453-461, 2007.

[46] P. V. Joseph, G. Mathew, K. Joseph, G. Groeninckx, and S. A. Thomas, "Dynamic mechanical properties of short sisal fibre reinforced polypropylene composites," Composites Part A: Applied Science and Manufacturing, vol. 34, no. 3, pp. 275-290, 2003.

[47] A. R. Sanadi, J. F. Hunt, D. F. Caulfield, G. Kovacsvolgyi, and B. Destree, "High fibre-low Matrix composites: kenaf fibre/polypropylene," in Proceedings of the 6th International Conference on Woodfibre-Plastic Composites, pp. 121-124, Madison, Wis, USA, May 2001.

[48] I. D. Danjaji, R. Nawang, U. S. Ishiaku, H. Ismail, and Z. A. M. Mohd Ishak, "Degradation studies and moisture uptake of sago-starch-filled linear low-density polyethylene composites," Polymer Testing, vol. 21, no. 1, pp. 75-81, 2002.

[49] S. Das, A. K. Saha, P. K. Choudhury et al., "Effect of steam pretreatment of jute fiber on dimensional stability of jute composite," Journal of Applied Polymer Science, vol. 76, no. 11, pp. 1652-1661, 2000.

[50] J. Gassan and A. K. Bledzki, “The influence of fiber-surface treatment on the mechanical properties of jute-polypropylene composites," Composites Part A: Applied Science and Manufacturing, vol. 28, no. 12, pp. 1001-1005, 1997.

[51] B. Yang, Z. Dai, S.-Y. Ding, and C. E. Wyman, "Enzymatic hydrolysis of cellulosic biomass," Biofuels, vol. 2, no. 4, pp. 421450, 2011.

[52] T. T. Mohammad and S. Narges, "Biodegradation behaviours and water absorption of polypropylene alcohol/starch/carboxymethyl cellulose/clay nanocomposites," International Nano Letters, vol. 3, no. 5, pp. 1-8, 2013.

[53] I. Michael, "Study of cellulose interaction with concentrated solutions of sulfuric acid," ISRN Chemical Engineering, vol. 2012, Article ID 428974, 7 pages, 2012.

[54] N. A. Azahari, N. Othman, and H. Ismail, "Biodegradation studies of polyvinyl alcohol/corn starch blend films in solid and solution media," Journal of Physical Science, vol. 22, no. 2, pp. 1531, 2011. 

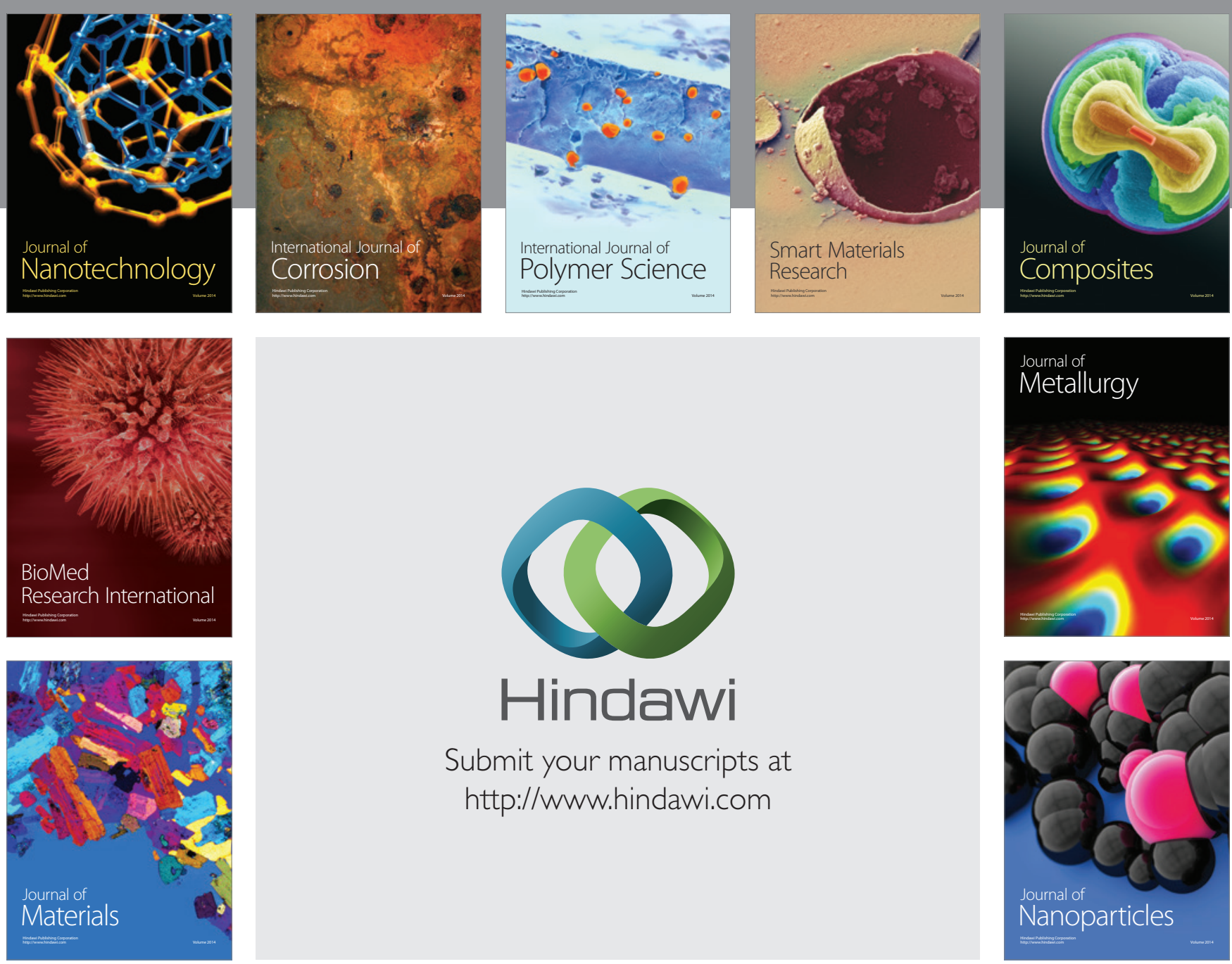

Submit your manuscripts at http://www.hindawi.com
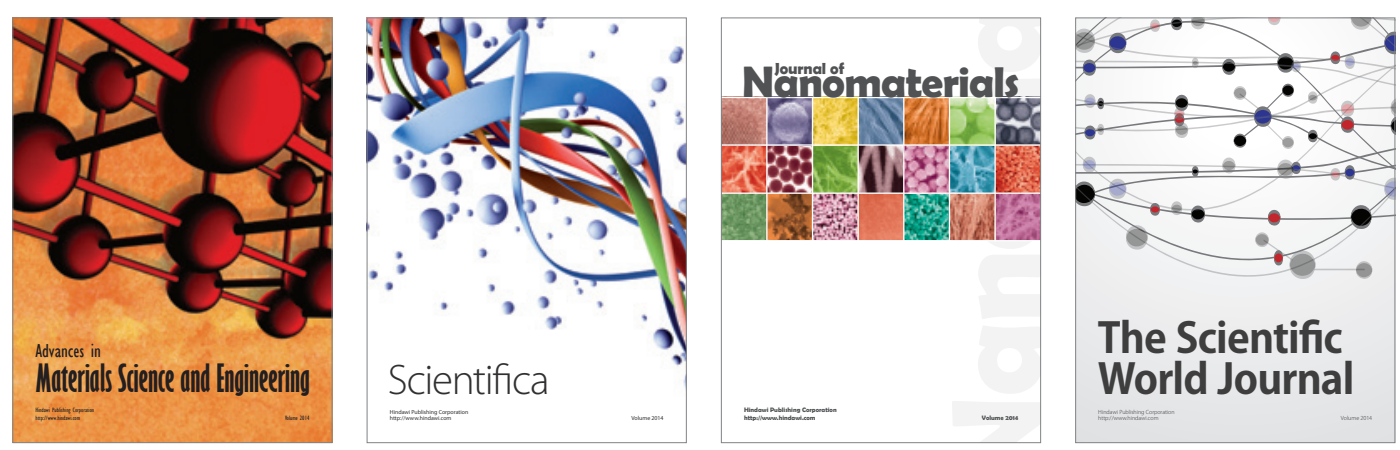

\section{The Scientific World Journal}
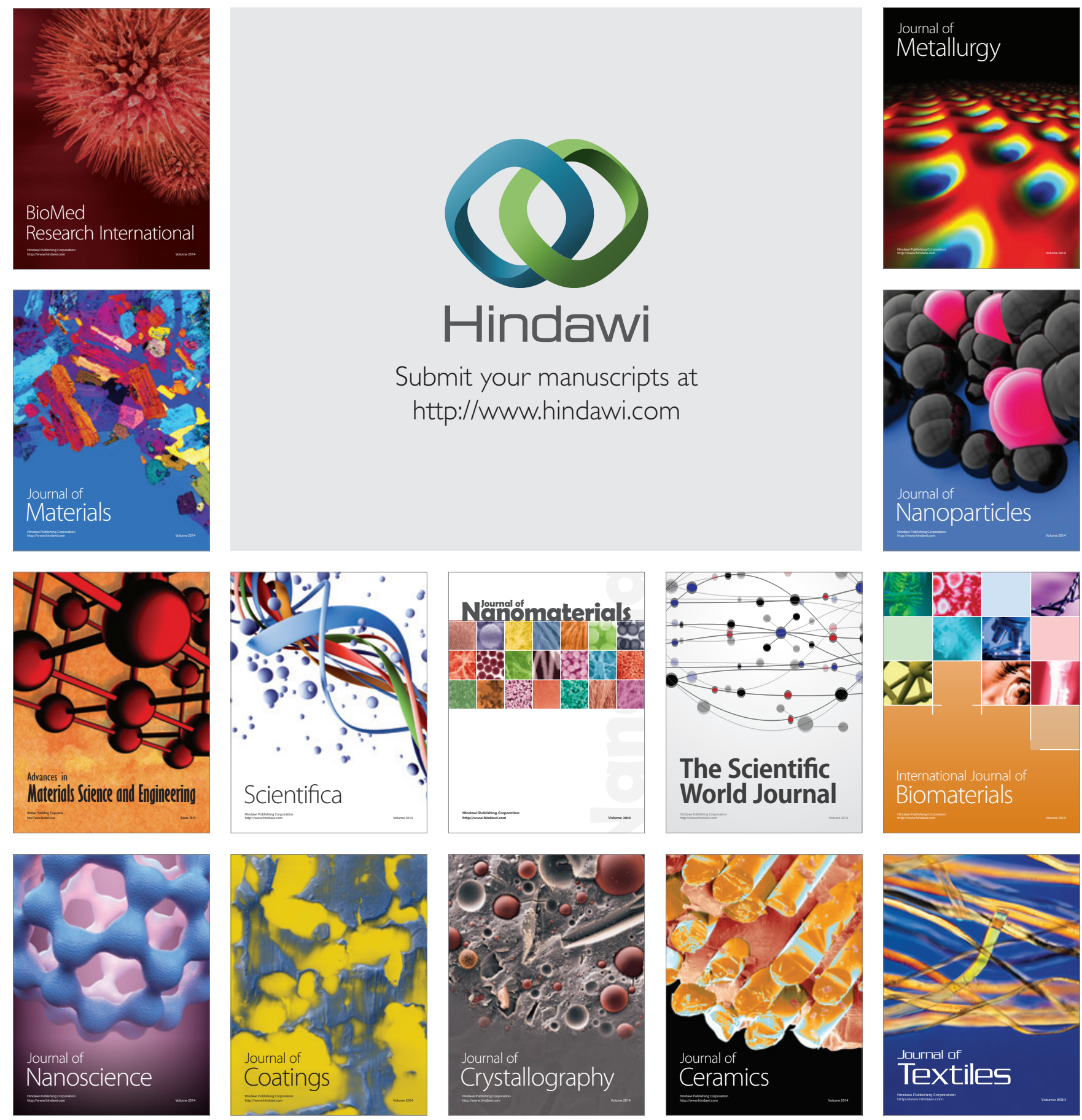